\title{
Optimizing rock cutting through computer simulation
}

\author{
J. Rojek \\ E. Oñate \\ C. Labra \\ H. Kazal \\ J. Akerman
}




\section{Optimizing rock cutting through computer simulation}

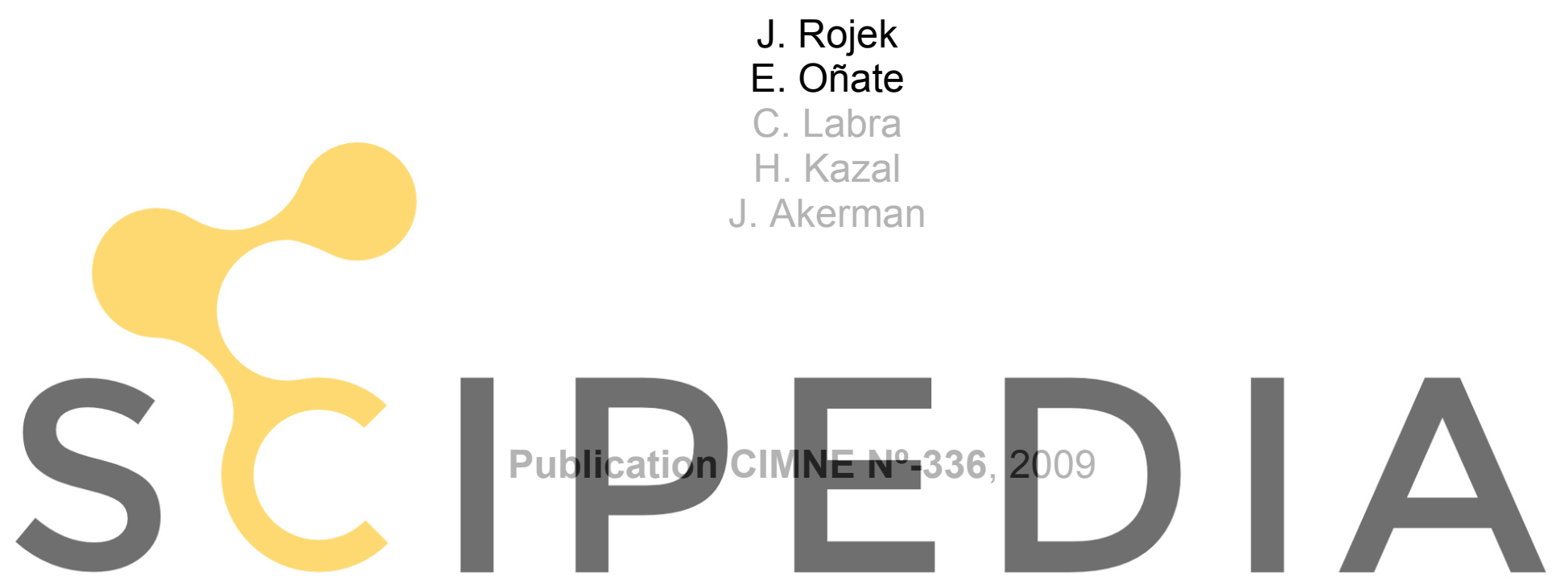

Register for free at https//www.scipedia.com to download the version without the watermark 


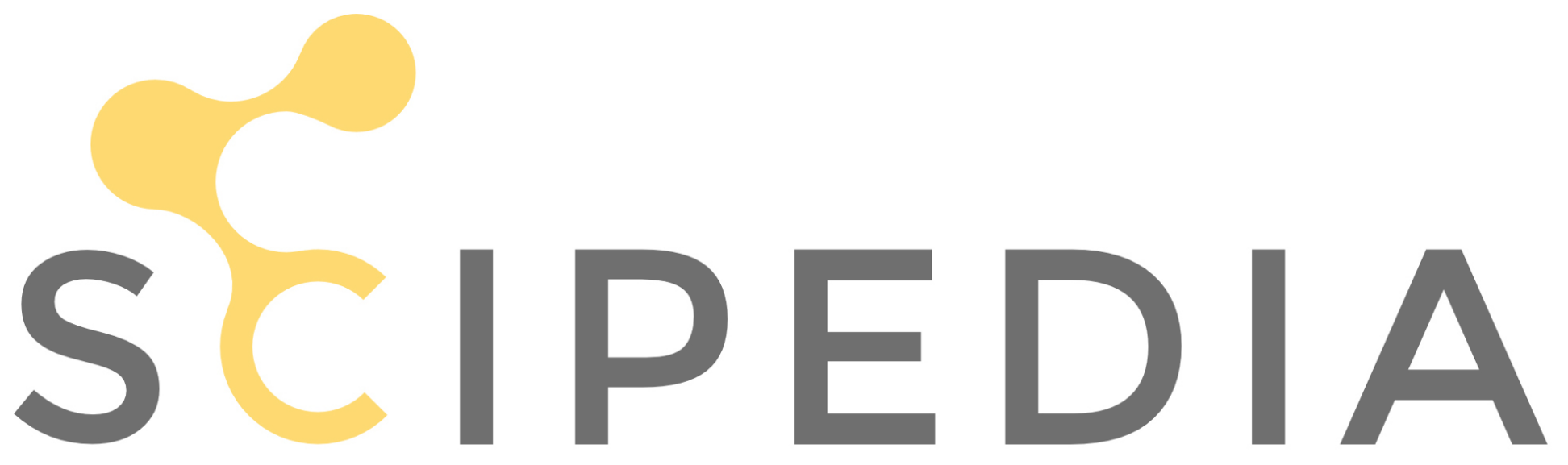

Register for free at https//www.scipedia.com to download the version without the watermark 


\title{
Optimizing rock cutting through computer simulation
}

\author{
Jerzy Rojek ${ }^{1}$, Eugenio Oñate ${ }^{2}$, Carlos Labra ${ }^{2}$, Hubert Kargl $^{3}$, Jan Akerman ${ }^{3}$ \\ ${ }^{1}$ Institute of Fundamental Technological Research, Warsaw, Poland \\ ${ }^{2}$ International Center for Numerical Methods in Engineering, Barcelona, Spain \\ ${ }^{3}$ Sandvik Mining and Construction G.m.b.H., Zeltweg, Austria
}

This paper presents an original thermomechanical model of rock cutting with evaluation of tool wear. The model has been developed within the framework of the discrete element method, which is a suitable numerical method to study problems of multiple material fractures like those of rock cutting. The paper presents brief overview of the theoretical formulation, calibration of the discrete element model, and a number of numerical results obtained in simulation of rock cutting processes typical for underground excavation, using both roadheaders and TBMs.
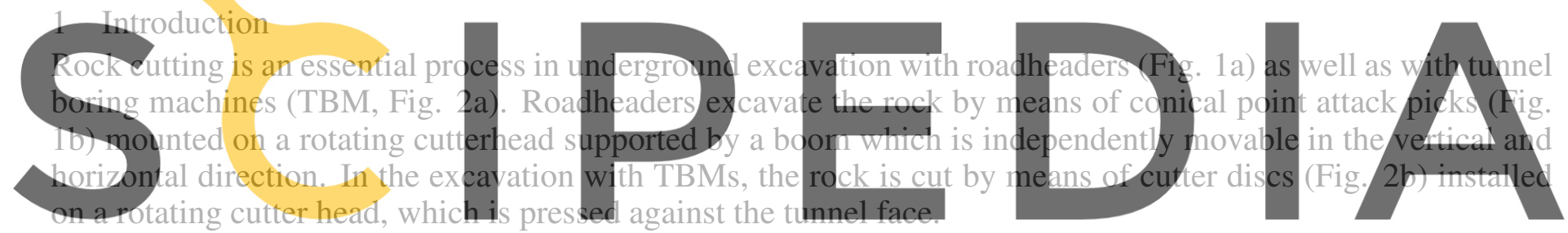

The objective of the cutting process optimization is to maximize cutting efficiency at an acceptable cost.

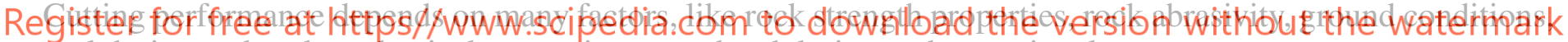
tool design and tool mechanical properties, cutterhead design and operational parameters.

Cuttability of specific rocks and performance of cutting tools can be studied experimentally. Scale-one cutting tests with a single roadheader pick can be performed on the cutting testrig (Fig. 3) built in the laboratory of SANDVIK Mining and Construction (Zeltweg, Austria). The representative experimental procedure for TBM cutter discs is based on the linear cutting test (Chang et al. 2006).

Rock cutting process can also be analyzed by computer simulation. Numerical modelling of rock cutting requires special non-standard approaches. Finite element models based on continuum mechanics have seri-

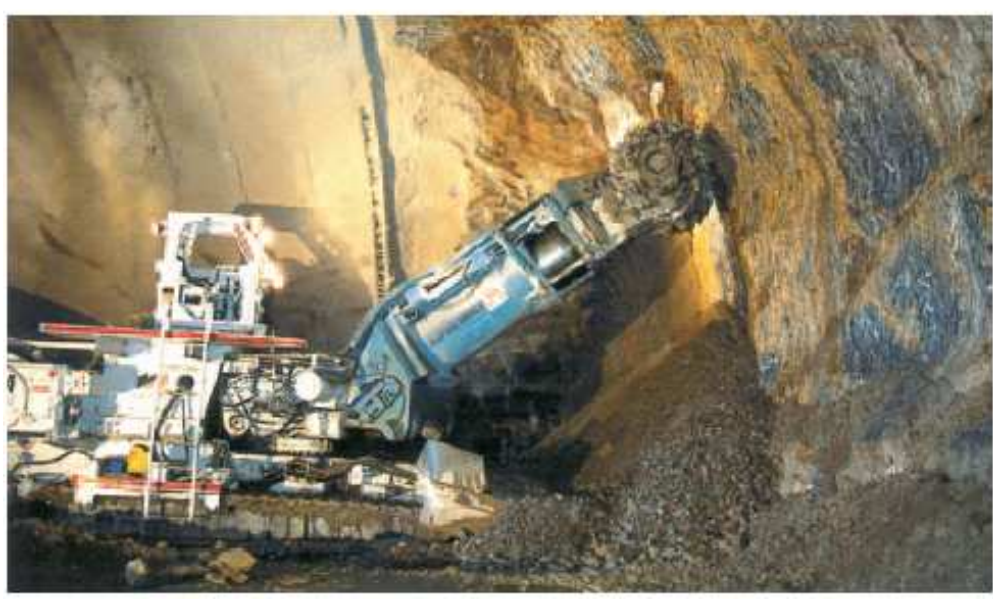

a)

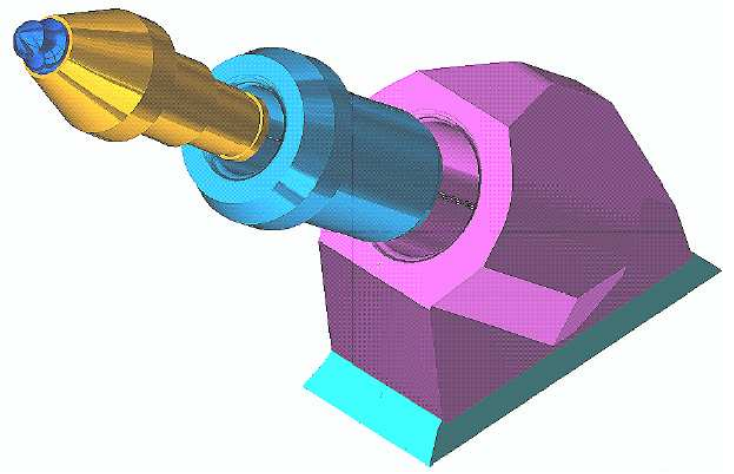

b)

Figure 1: Roadheader: a) rock excavation with a roadheader, b) typical design of a point attack pick. 


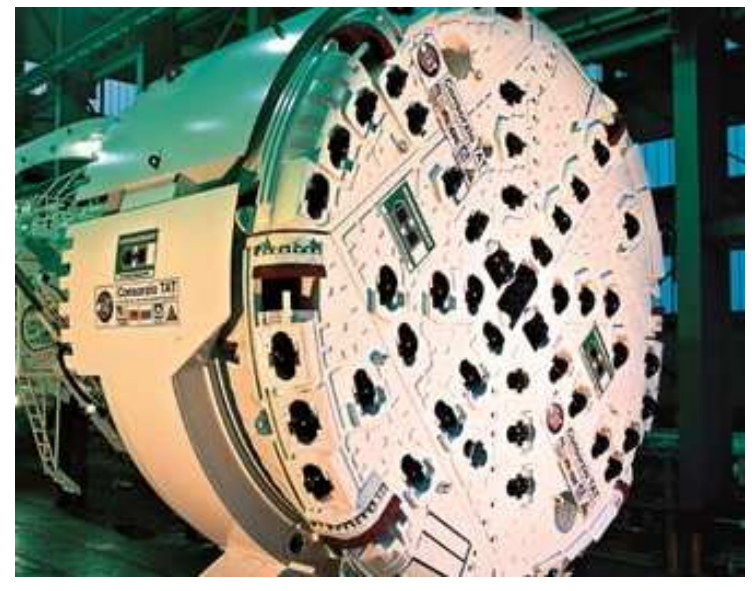

a)

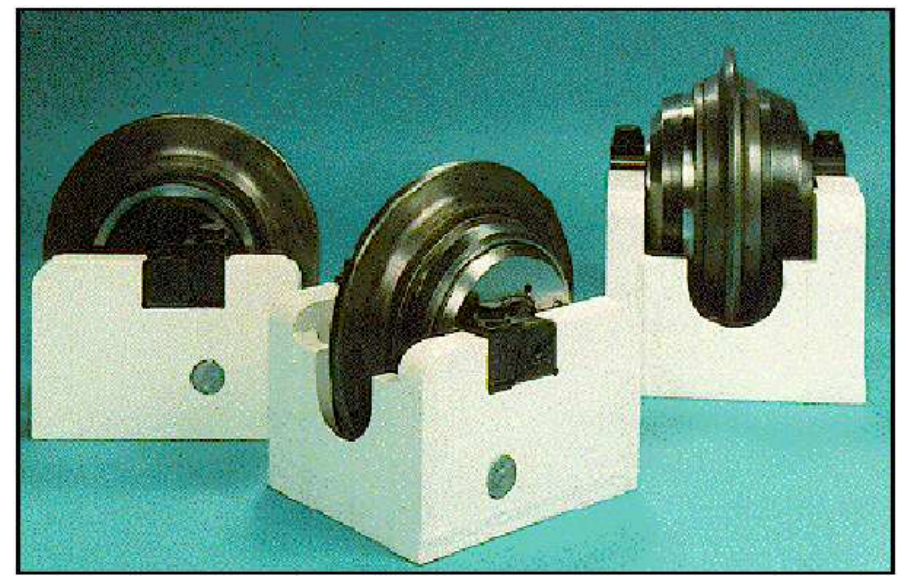

b)

Figure 2: TBM design: a) general view of the Herrenknecht Gripper TBM, b) single disc cutter.

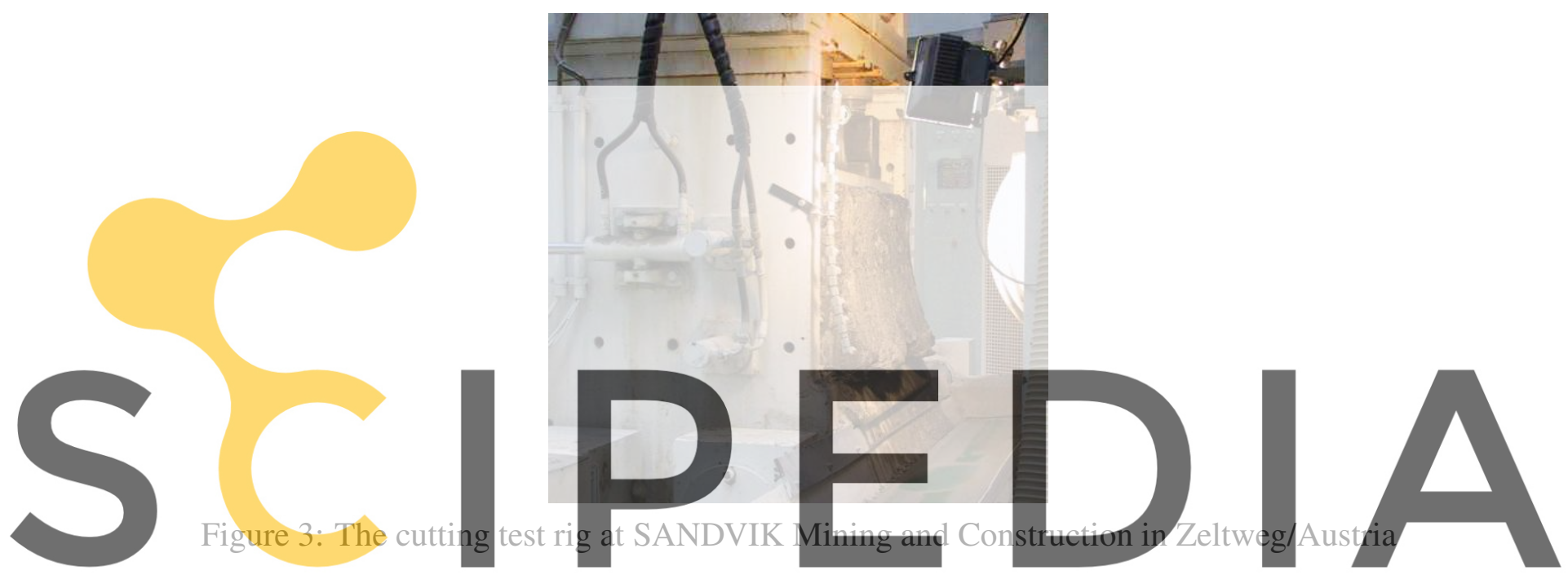

ous problems in modelling discontinuities of the material occuring during rock cutting. An original numerical

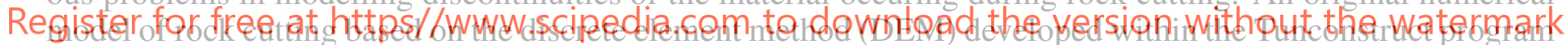
proved to be very useful in studying rock cutting processes. The DEM model is a suitable method to represent discontinuous material failure with multiple fracturing. Numerical model allows us to quantify cutting forces, tool wear and tip temperatures of different cutting tools in different types of rock under specific cutting parameters. It can be treated as an alternative or supplementation to laboratory cutting tests.

\section{Tool-rock interaction}

For optimization of the cutting system for different rock conditions, understanding of the tool-rock interaction is essential. In all rock cutting processes rock is desintegrated under the action of a tool. Rock failure mechanisms depend on rock properties. The failure is initiated in the zone under the tip of the tool (a roadheader pick or cutter disc of a TBM), where rock is crushed under high compressive stresses. Force exerted by the tool is transmitted through the crushed zone to the intact rock and microcracks are initiated at the boundary between the crushed zone and the intact rock. The cracks initiated at the crushed zone propagate through the rock. Fractures propagating to the rock surface separate chips from the intact rock. Chip formation is the most desirable failure mechanism in the rock cutting, since it is favourable for the low process energy and low tool wear.

Cutting forces depend on many factors, most important being rock strength and brittleness, tool geometry and its orientation, cutting depth and cutting velocity. The tool is subjected to dynamic loads coming from the tool impacts on the rock surface as well as force oscillations due to chip separations. The tool design and material must ensure its resistance to high impact loading.

High contact forces and relative motion at the tool-rock interface produce high frictional forces. Intensive heat generation at the frictional contact during cutting results in high temperatures of the tool surface. In some cases temperature on the tool surface can reach as much as $550-800^{\circ} \mathrm{C}$, cf. (Verhoef 1997; Loui and Karanam 2005). High temperature may soften the tool material, which can lead to excessive tool deformation (Fig. 4a). High temperature is also disadvantageous for the tool resistance to wear. 


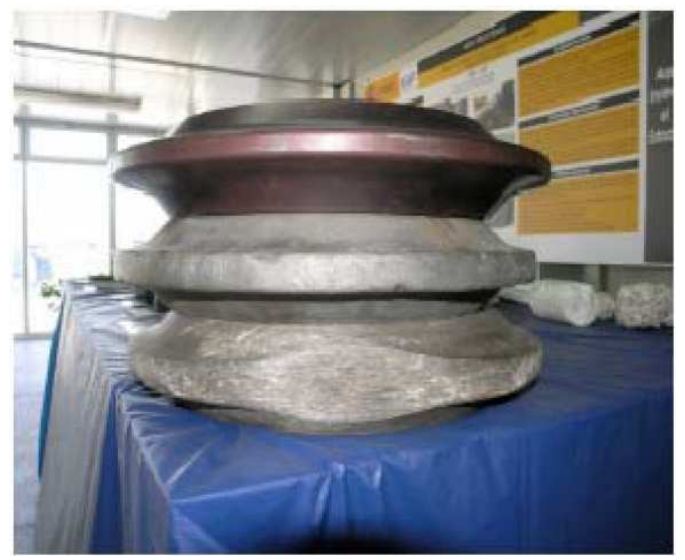

a)

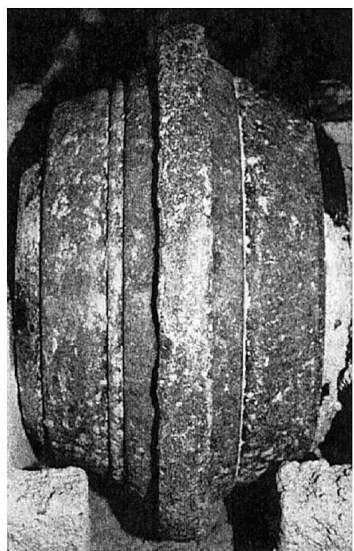

b)

Figure 4: Typical failures of TBM cutter discs: a) excessive plastic deformation, b) excessive wear (courtesy of Herrenknecht AG).

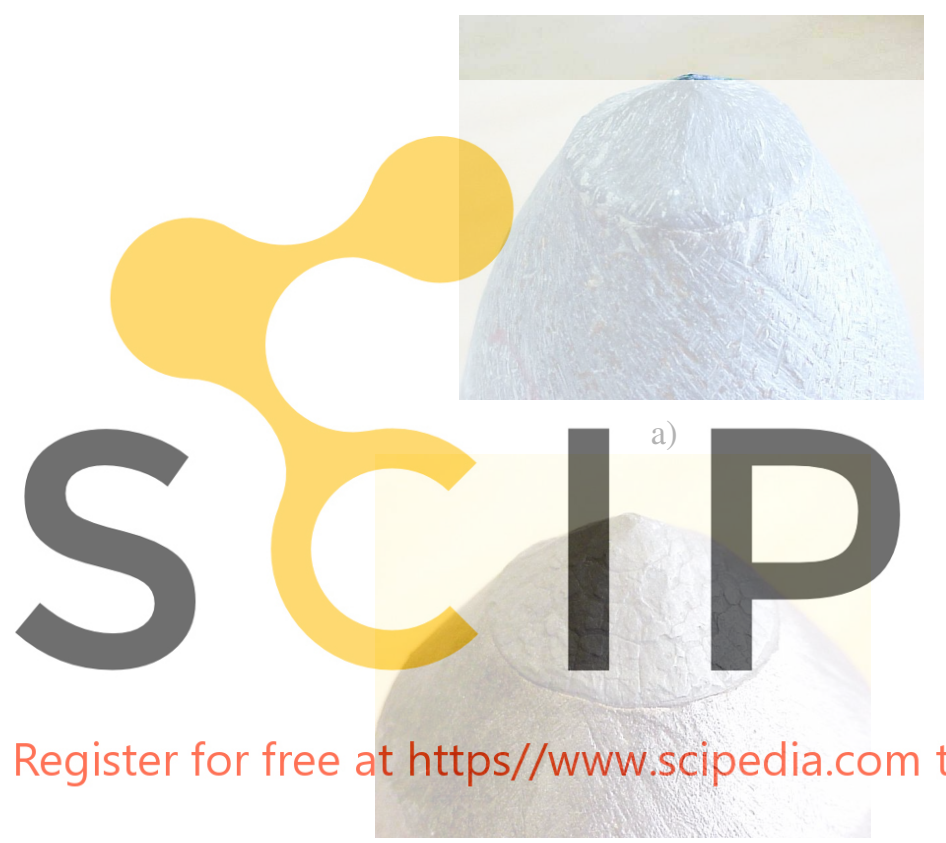

c)

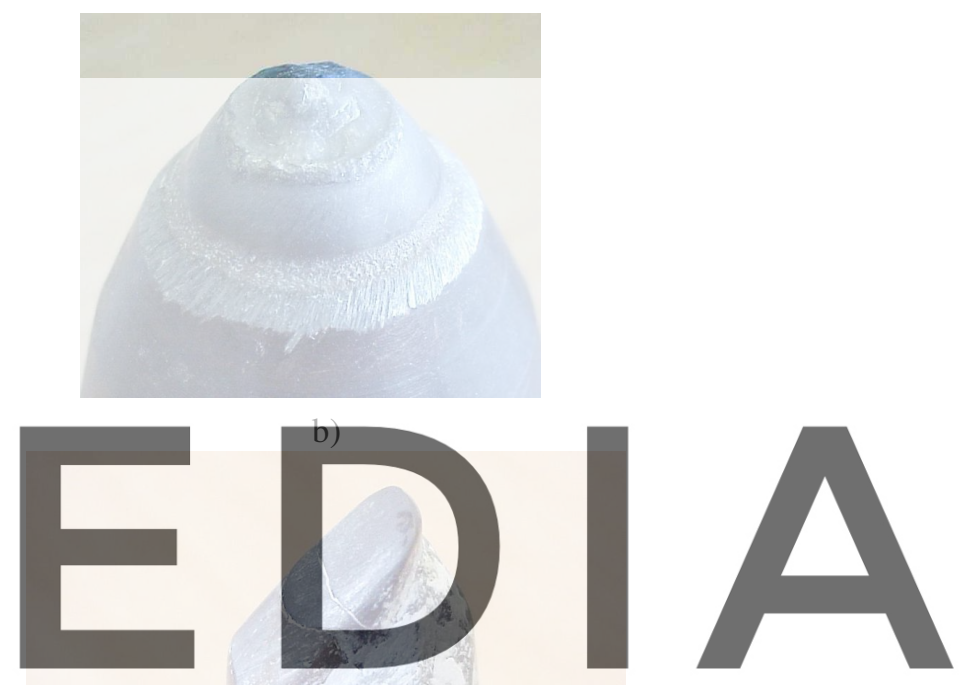

download the version without the watermark

d)

Figure 5: Different roadheader pick failure mechanisms in cutting of hard rocks: a) abrasive wear, b) adhesive wear, c) surface fatigue and abrasion, d) adhesion and fatigue

3 Wear of rock cutting tools

High tool wear is one of the principal obstacles that arise during the excavation by rock cutting. Changes of pick geometry due to wear lead to difficulties in the tool penetration reducing thus cutting performance. Frequent work breaks necessary for the tool change reduce the efficiency further. Increased use of cutting tools contribute to overall cost increase. Therefore prediction of wear is important in the tool design and excavation planning.

Wear is a very complicated process of progressive loss of the material from the tool surface. It occurs in all cutting tools, example of worn TBM cutter discs and roadheader picks are shown in Figs. 4b and 5, respectively. Practical observations show that different wear mechanisms can occur in rock cutting tools (Akerman 2006).

Figure 5 shows different wear patterns of roadheader picks. Abrasive wear (Fig. 5a) is one of the most important mechanisms in cutting of hard rocks especially in the presence of quartzite. Scraping of the rock surface leads to high temperatures, which softens the steel body and hardmetal tip, resulting in increasing wear of adhesive character (Fig. 5b). Adhesive wear is typical for heat generating rock of low abrasivity (Fig. $5 \mathrm{~d})$. In the field of rock and ground excavation it is very rare that just one wear mechanism occurs. Different mechanisms can act in parallel, as it is shown for instance in Figs. 5c,d.

Wear of rock cutting tools depends on many factors, such as (Verhoef 1997): rock/soil properties (strength, hardness, fracture properties, brittleness, abrasive capacity), tool characteristics (material properties, strength, hardness, geometry), cutting process parameters (position of a tool with respect to rock (penetration depth, rake 
and cutting angles, cutting velocity, cutting forces, heat generation, cooling, temperature) to name the most important ones.

\section{Thermomechanical model of rock cutting}

The numerical model of rock cutting developed within the Tunconstruct project, covers all the most important phenomena identified in the previous sections, that is rock failure mechanisms, tool-rock interaction, frictional heat generation, tool temperature increase and tool wear. Rock cutting is analysed as a thermo-mechanical process. Thermo-mechanical model of rock cutting is shown schematically in Fig. 6. The tool-rock system is considered. The main physical phenomenon analyzed in the mechanical problem is the interaction of the tool with a rock leading to a failure of the rock characterized with discontinuous material behaviour. Interaction forces between the tool and rock are determined. Simultaneously heat generated by friction between the tool and rock is calculated and passed to the thermal model. Thermal model takes into account heat absorption and conduction through the tool and rock as well as convective heat transfer on the free surface of the rock and tool and heat transfer in the contact surface between the rock and tool.

A numerical model representing the thermomechanical phenomena described above has been developed within the framework of the discrete element method (DEM) (Rojek 2007). Rock material is modelled using the spherical (in 3D) or cylindrical (in 2D) discrete elements. The tool is considered to be rigid in our numerical model assuming that its stiffness is sufficient to produce rock failure and its deformation is irrelevant for the purposes of modelling of rock failure. The DEM is a suitable tool to model rock failure characterized by numerous discontinuities (Huang 1999; Oñate and Rojek 2004). Discrete element formulation using spherical or cylindrical particles was first proposed by Cundall and Strack (1979) and by Cundall (1988). In the present work the computer code Simpact is used with the implementation of the discrete element algorithm (Rojek et al. 2001; Oñate and Rojek 2004).

Within the DEM, it is assumed that a solid material can be represented as a collection of rigid particles/blocks interacting among themselves in the normal and tangential directions. The normal and tangential contact forces,

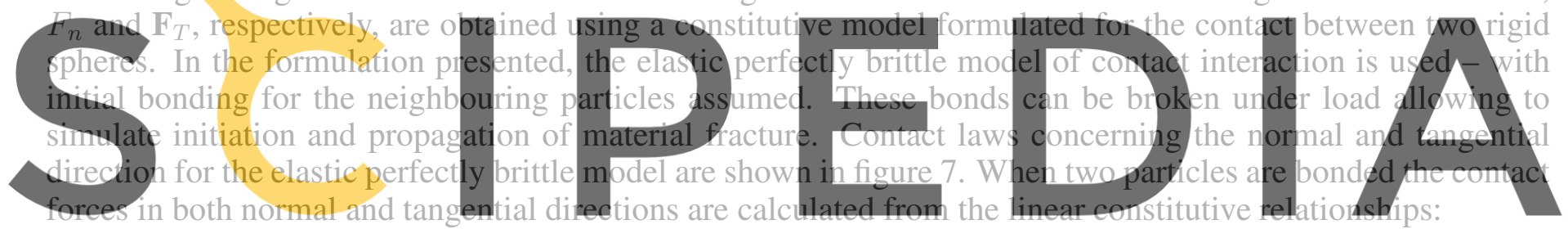

\section{Register for free at https//www.scipediak.com to Edown to}

where: $k_{n}$ - interface stiffness in the normal direction, $k_{t}$ - interface stiffness in the tangential direction, $u_{n}$ — normal relative displacement, $\mathbf{u}_{t}$ - tangential relative displacement.

The tensile and shear contact forces are limited by the tensile and shear interface strengths, $R_{n}$ and $R_{t}$, respectively:

$$
F_{n} \leq R_{n}, \quad\left\|\mathbf{F}_{t}\right\| \leq R_{t}
$$

Cohesive bonds are broken instantaneously when the interface strength is exceeded either by the tangential contact force or by the tensile contact force.

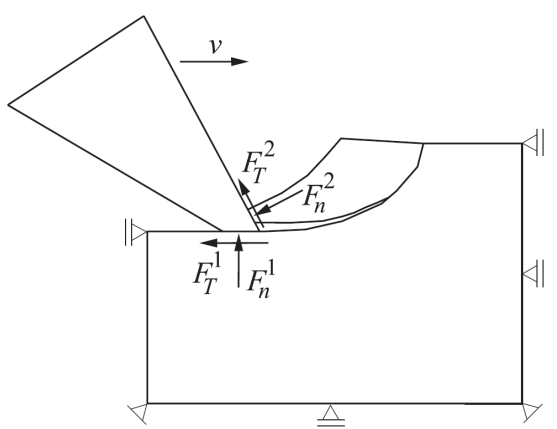

a)

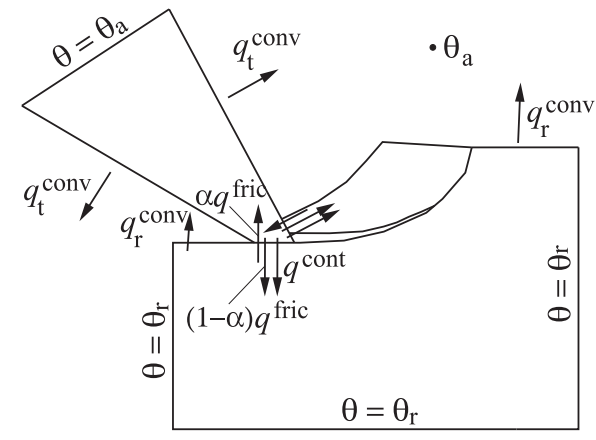

b)

Figure 6: Thermo-mechanical model of rock cutting: a) scheme of mechanical problem, b) scheme of thermal problem. 


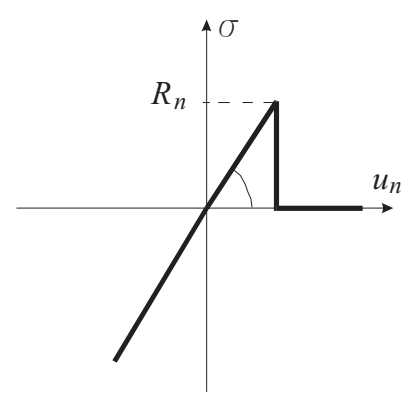

a)

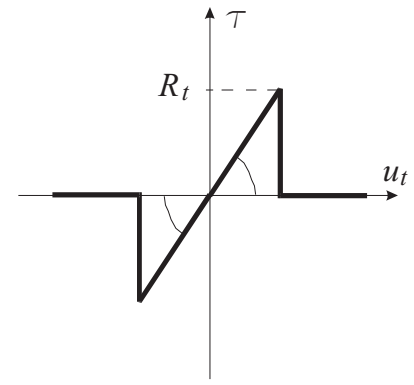

b)

Figure 7: Force-displacement relationships for the elastic perfectly brittle model: a) in the normal direction, b) in the tangential direction

In the absence of cohesion the normal contact force can be compressive only $\left(F_{n} \leq 0\right)$ and tangential contact force can be nonzero due to friction. In the present formulation the Coulomb model of friction is used. The tool-rock interaction is also modelled using the frictional contact model.

Thermal phenomena during rock cutting are described by the heat balance equation. Particle-to-particle conductive heat transfer rate $Q_{i j}^{\text {cont }}$ is assumed in the form analogical to the Fourier equation

$$
Q_{i j}^{\text {cont }}=h^{\text {cond }}\left(T_{i}-T_{j}\right)
$$

with $h^{\text {cond }}$ being the heat transfer coefficient between material particles, which can be determined as a function of the solid heat conductivity and particle configuration. Heat generation through frictional dissipation is calculated using the following formula

$$
Q_{i}^{g e n}=\chi\left|F_{T} v_{T}\right|
$$

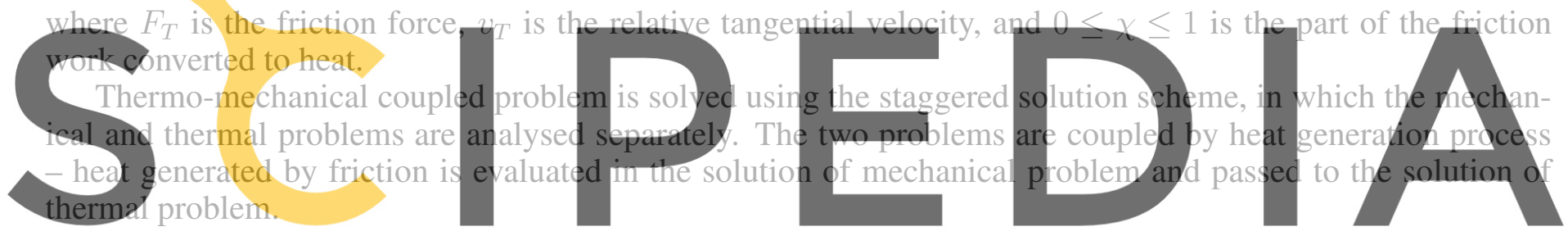

Register for free at https//www.scipedia.com to download the version without the watermark Evaluation of wear and lts evolution is included in the numerical model developed. Quantification of wear is based on the classical formula of Archard (1953), which is still widely used. It assumes that the wear rate $\dot{w}$ is proportional to the contact pressure $p_{n}$ and to the slip velocity $v_{T}$

$$
\dot{w}=k \frac{p_{n} v_{T}}{H}
$$

where $H$ denotes the hardness of worn surface and $k$ is a dimensionless wear parameter. The Archard model was derived originally for adhesive wear, the same form of equation, however, can be obtained for abrasive wear, cf. (Rabinowicz 1995). Values of adhesive and abrasive wear constants $k$ for different combinations of materials can be determined in laboratory tests. Influence of temperature on wear can be considered by adaptation of the Archard equation (5) taking the hardness $H$ changing with temperature $T$

$$
\dot{w}=k \frac{p_{n} v_{T}}{H(T)}
$$

The tool wear $w$, i.e. the amount (depth) of removed material, is obtained by integrating the wear rate $\dot{w}$ in time

$$
w=\int \dot{w} \mathrm{~d} t .
$$

The Archard law given by Eq. (6) has been implemented in the numerical algorithm. Distribution of wear on the tool surface can be estimated and the tool shape can be modified according to the calculated wear.

Wear is a relatively slow process and it can be observed only after many work cycles. In the numerical algorithm developed wear is accelerated using scaled wear constants. Thus visible wear is obtained after the analysis of one cycle only. 
The developed numerical algorithm of wear evaluation takes advantage of the tool discretization with discrete elements. This allows us to easily modify the shape of the tool. The tool shape is changed eliminating particles if the accumulated wear exceeds the particle diameter. The tool shape is modified continuously during the analysis. Alternatively the tool surface can be discretized with finite-element-type mesh. In this case the profile of wear and its evolution is evaluated on the discretized surface.

\section{Determination of rock model parameters}

Determination of rock model parameters is the first step in our simulation of rock cutting process. A set of micromechanical parameters has to be established to model required macroscopic properties of the rock material, which will be considered in rock cutting simulation.

The most important macroscopic properties are Young modulus $E$, Poisson ratio $\nu$ and compressive and tensile strengths, $\sigma_{c}$ and $\sigma_{t}$, respectively. Microscopic parameters are, in turn, all the constitutive model parameters governing the interaction between a pair of particles: the normal and tangential stiffness $k_{n}$ and $k_{T}$, the interface strengths in the normal and tangential directions, $R_{t}$ and $R_{t}$, respectively.

A sandstone with the following macroscopic properties: $E=18690 \mathrm{MPa}, \nu=0.23, \sigma_{c}=127.8 \mathrm{MPa}, \sigma_{t}=$ 12.3 MPa has been selected for experimental and numerical tests. Macroscopic material properties have been determined by laboratory tests, unconfined compression test and indirect tension (Brazilian) test, performed in the laboratory of Sandvik Mining and Construction GmbH (Zeltweg, Austria). Numerical simulation of these tests will allow to determine the microscopic constitutive parameters for a material sample modelled with discrete elements yielding the macroscopic properties of the real rock material. Figure 8 demonstrates failure modes of the sandstone sample under compressive load obtained in the laboratory test and in the numerical simulation. The failure modes obtained experimentally and numerically for the Brazilian test are shown in Fig. 9. A good agreement of the numerical solution with experimental results can be observed.
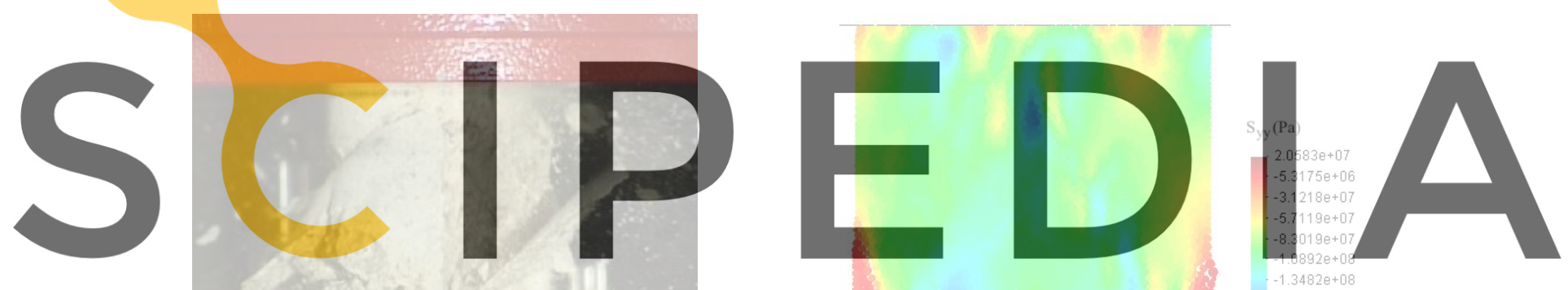

Register for free at https//www.scipedia.com to download the version withoul

a)

b)

Figure 8: Unconfined compression test: a) laboratory test, b) numerical simulation

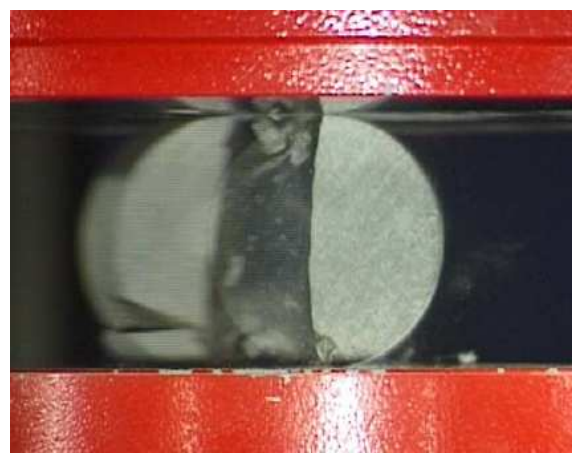

a)

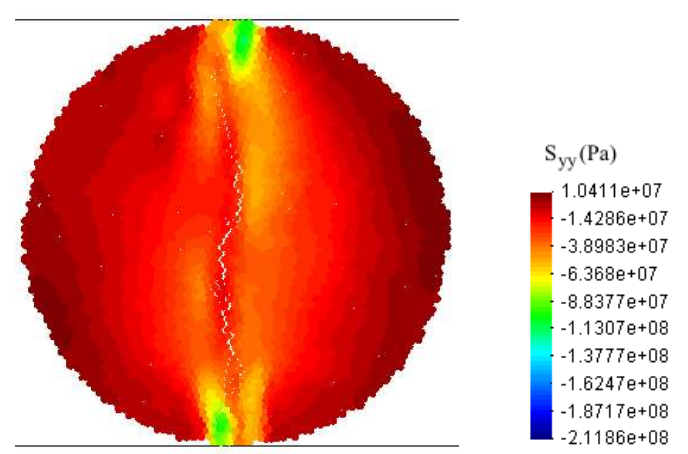

b)

Figure 9: Brazilian test: a) laboratory test, b) numerical simulation

The micromechanical parameters have been determined using the methodology developed in (Huang 1999) based on the Buckingham $\pi$ theorem which allows to assume the dimensionless relationships relating the microscopic parameters to macroscopic properties. The dimensionless relationships have been determined taking the results of numerical simulations of laboratory tests for a certain range of microscopic parameters. For the rock considered the following set of micromechanical parameters has been found for the DEM model: 
contact stiffness in the normal direction $k_{n}=1.61129 \cdot 10^{10} \mathrm{~Pa}$, contact stiffness in the tangential direction $k_{T}=0.3222 \cdot 10^{10} \mathrm{~Pa}$, cohesive bond strengths in the normal and tangential direction, $R_{n}=R_{T}=0.29 \cdot 10^{5}$ $\mathrm{N} / \mathrm{m}$. The parameters are valid for the DEM model of discs of radii $0.262-0.653 \mathrm{~mm}$, which were used in the numerical simulations of laboratory tests. Dimensionless relationships allow to scale this parameters for DEM models with other element sizes.

7 Simulation of rock cutting laboratory test

Validation of rock cutting model has been carried out comparing results of simulation of rock cutting with a single roadheader pick to experimental results obtained in a laboratory test performed in the laboratory of Sandvik Mining and Construction.

The scheme of the test rig is shown in Fig. 10a. A sandstone block is cut by a rotating tool. Mechanical properties of a rock are the same as those determined experimentally in section 6: compressive strength $\sigma_{\mathrm{c}}=127$ $\mathrm{MPa}$ and tensile strength $\sigma_{\mathrm{t}}=12 \mathrm{MPa}$. Performance of rock cutting is shown in Fig. 10b. Splitting of chips typical for brittle rock cutting can be seen.
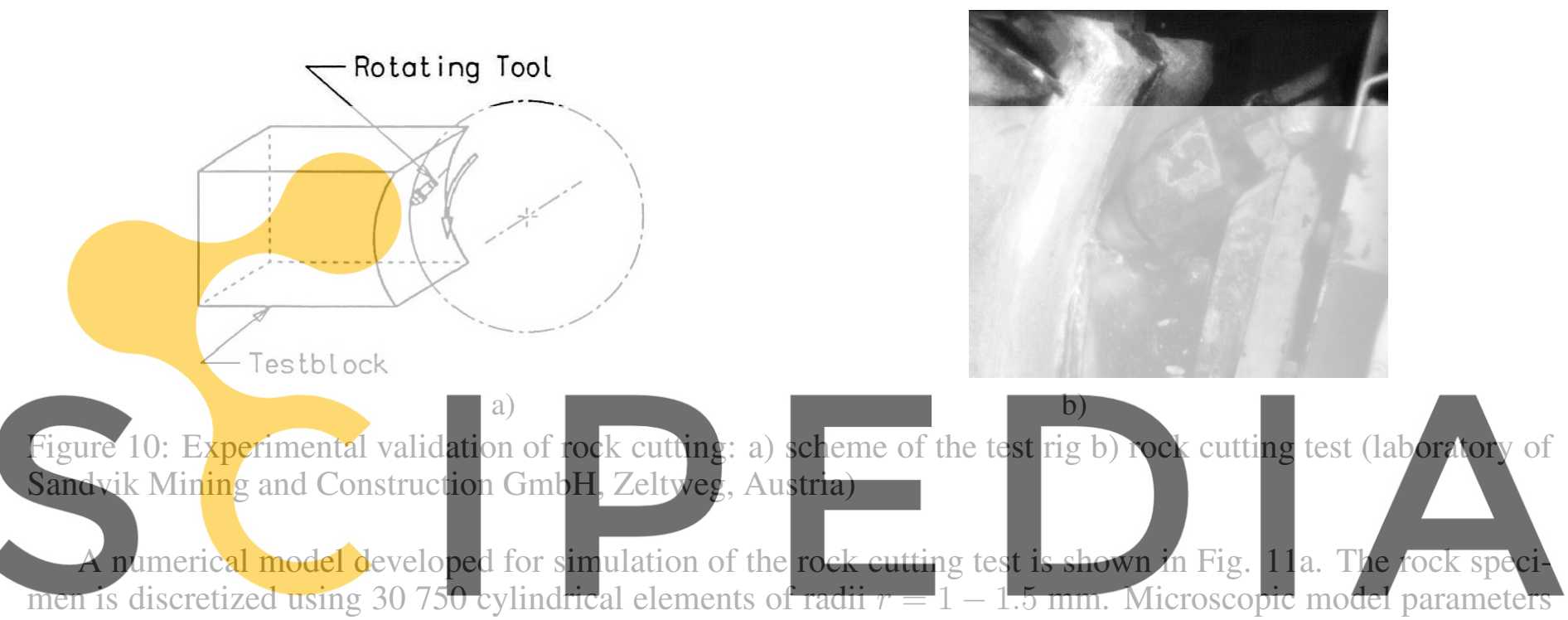

determined in the previous section have been scaled considering the change of the element size.

Register for free at https//www.scipedia.com to download the version without the watermark

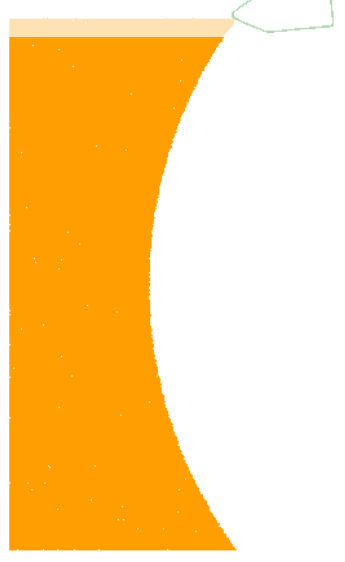

a)

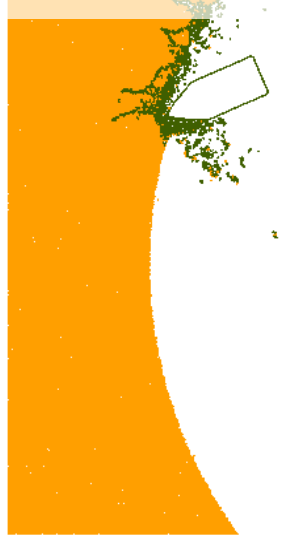

b)

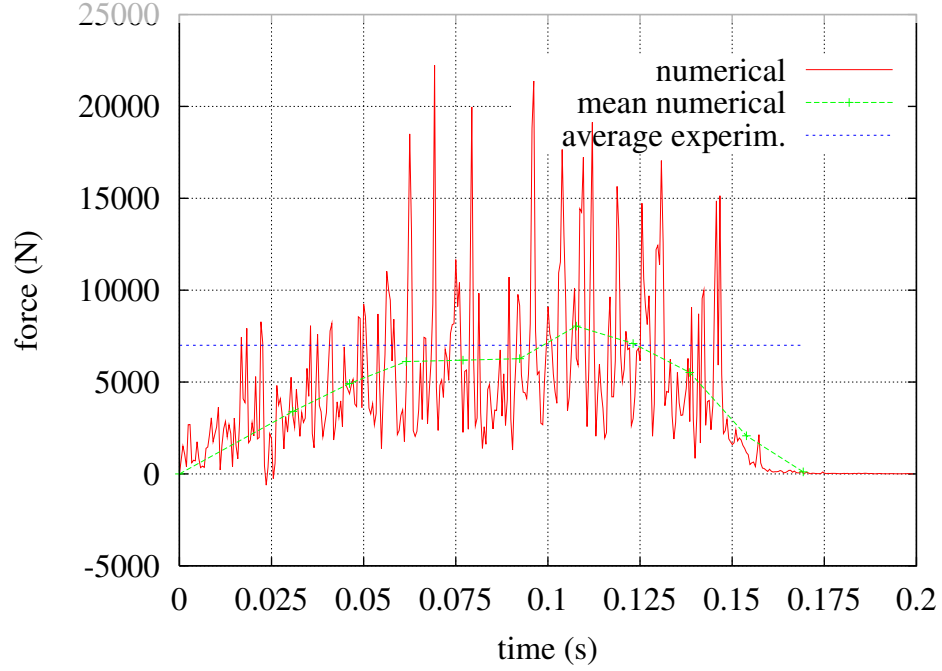

c)

Figure 11: Numerical simulation of rock cutting: a) numerical model, b) failure mode during rock cutting b) cutting force variation

The cutting tool has been considered as rigid, allowing to take into account its surface only. For the rocktool interaction the following set of parameters has been assumed: $k_{\mathrm{n}}=k_{\mathrm{s}}=5 \cdot 10^{10} \mathrm{MPa}, \mu=0.5$. Figure $11 \mathrm{~b}$ shows the rock failure mode obtained in the simulation. A satisfying accordance with the failure observed 
in the laboratory test can be seen. Figure $11 \mathrm{c}$ shows variation of the cutting force obtained in the numerical simulation. The value of the force corresponds to the distance between subsequent cuts. In the laboratory test the three components of the force on the tool tip have been registered, however, only its average values have been made available to comparison in this paper. As it can be seen in Fig. 11c the mean cutting force from the numerical analysis agrees quite well with the average experimental force (about $7000 \mathrm{kN}$ ).

8 Simulation of rock cutting with wear evaluation

Simulation of rock cutting with one pick of a roadheader has been analysed using a model shown in Fig. 12a. A sample of rock and one pick of a cutter head have been modelled. Mechanical properties of the rock are the same as for the sandstone studied experimentally and numerically in sec. 6. Material sample is represented by an assembly of randomly compacted 92000 discs of radii 1-1.5 mm. Model parameters used for sandstone in Sec. 7 are assumed for the micromechanical model. The following set of parameters has been assumed for the rock-tool interaction: $k_{\mathrm{n}}=k_{\mathrm{s}}=5 \cdot 10^{10} \mathrm{MPa}, \mu=0.4$.

The swing velocity of the cutter head was assumed $0.2 \mathrm{~m} / \mathrm{s}$, and angular velocity $1.6204 \mathrm{~s}^{-1}$, which with the distance of the tooth from the axis of rotation $0.7 \mathrm{~m}$ gives circumferential velocity $1.134 \mathrm{~m} / \mathrm{s}$.

Thermomechanical analysis with wear evaluation has been carried out. Results of the analysis are shown in Figs. 12b-c. Failure of rock during cutting is shown in Fig. 12b. Failure, typical for brittle rock can be observed. Temperature evolution is shown in Fig. 12c, the highest temperature is observed in the contact zones, where the frictional heat is generated. The same area has maximum wear amounts as it is shown in Fig. $12 \mathrm{~d}$.

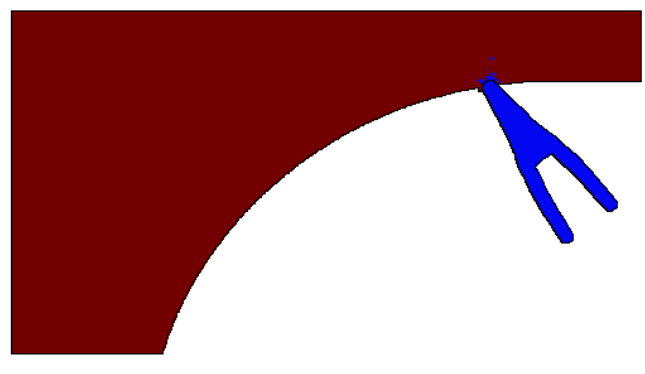

a)

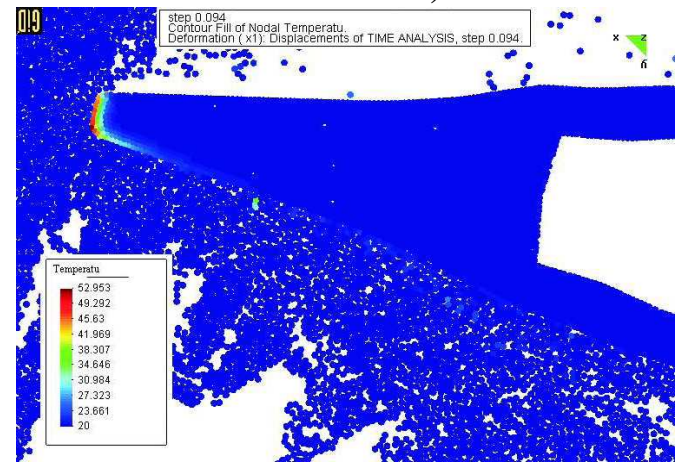

c)

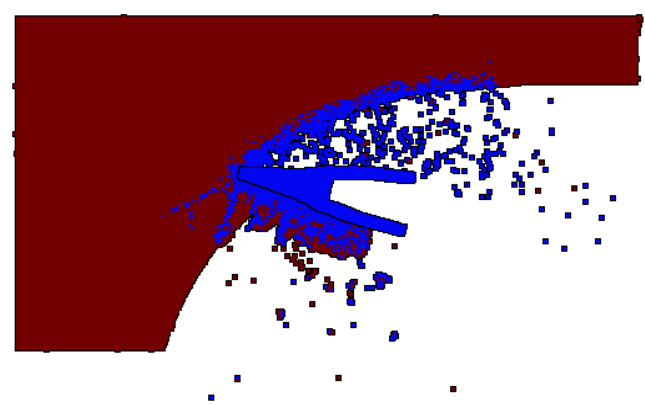

b)

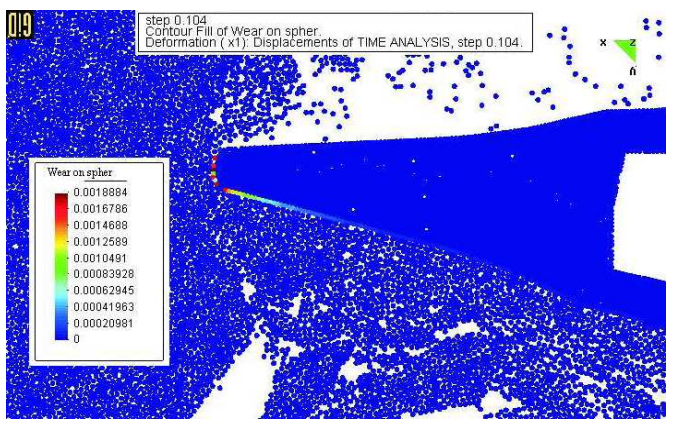

d)

Figure 12: Simulation of rock cutting with one pick of a road header: a) model geometry, b) failure mode, c) temperature evolution, d) accumulated wear on the tool surface

$93 \mathrm{D}$ simulation of the laboratory test of rock cutting

2D simulation of a cutting process with point attack picks of roadheader cannot predict all the three components of the cutting force. This can be achieved using a 3D discrete element model. Similarly as it was done for the 2D DEM model in Sec. 6, the 3D DEM model has been calibrated using the methodology combining simulations of the UCS and Brazilian tests with the dimension analysis based on the Buckingham $\pi$ theorem.

The 3D numerical model is shown in Fig. 13. Material sample has been discretized using 71,200 spherical particles. The results of the numerical simulation of the cutting test are shown in Fig. 14. Rock failure under the action of the tool and splitting of chips can be seen in this figure. The cutting forces obtained in simulations are plotted in Fig. 15. The numerical forces obtained are compared with average experimental forces. Quite a good agreement can be observed. 


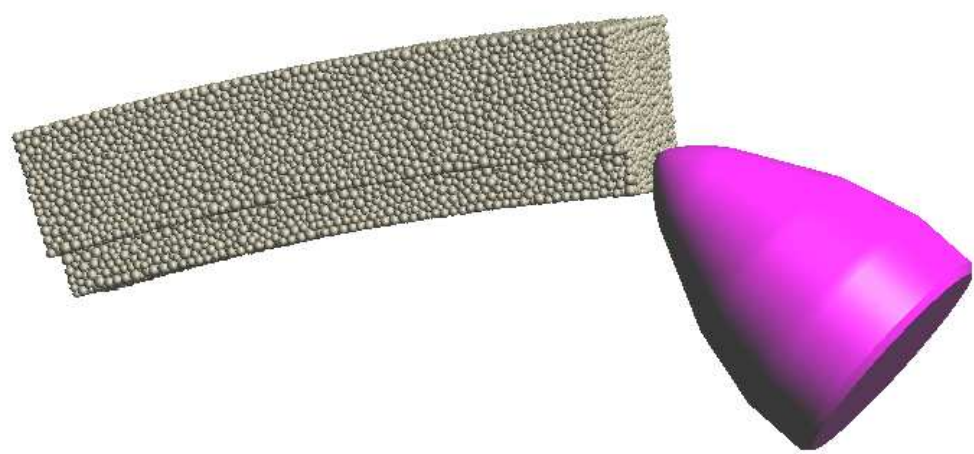

Figure 13: 3D numerical model of rock cutting

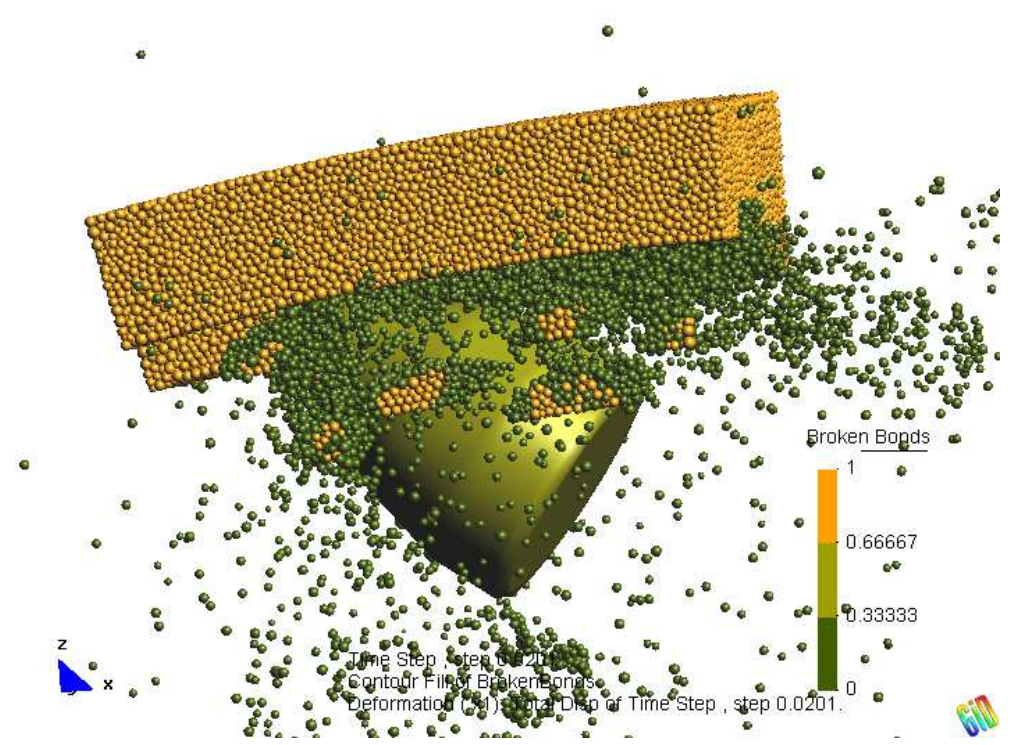

Figure 14: 3D numerical simulation of rock cutting

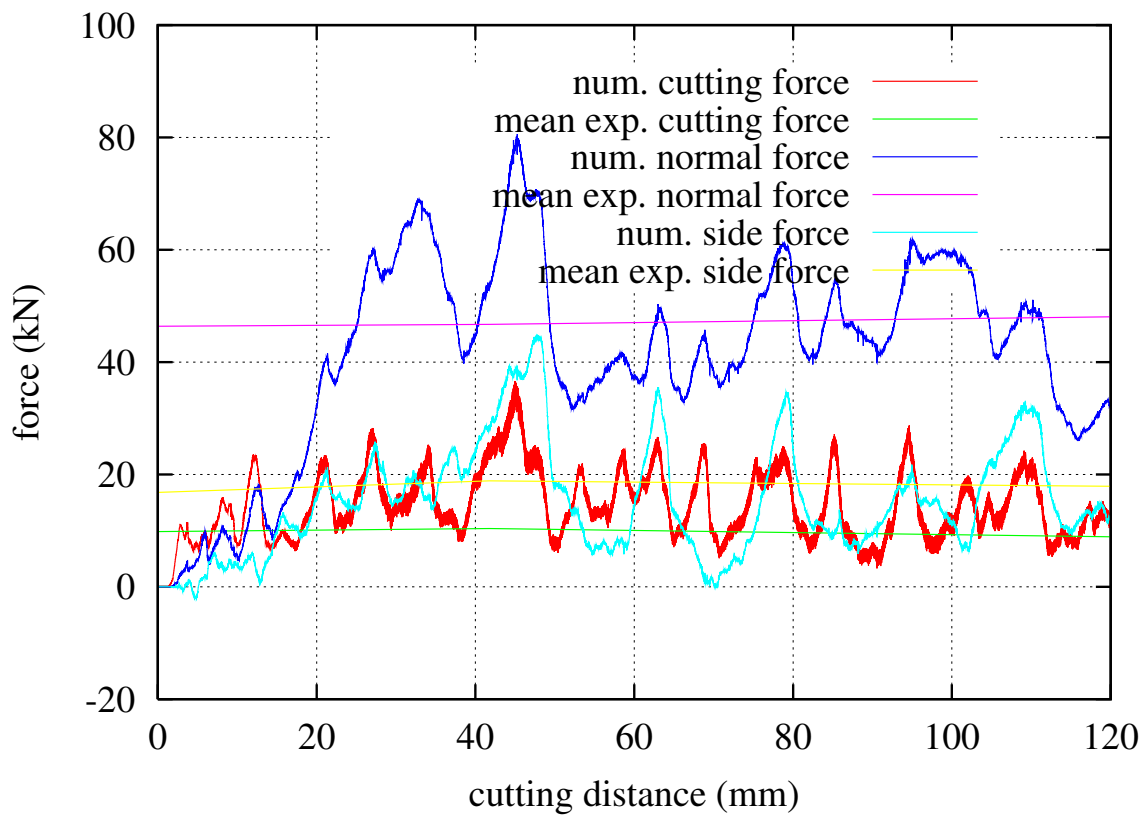

Figure 15: Cutting force components - comparison of numerical and average experimental results

The tools used in the laboratory tests of rock cutting have special tips made of copper, a soft material which is easily worn. This allowed us to obtain visible wear effects after few cuts (Fig. 16a). Evaluation of wear was included in the analysis. Evolution of the tool wear predicted by the analysis is shown in Fig. 16b. It can be seen that the wear pattern obtained in simulation agrees very well with the worn area observed in the tools used in laboratory tests. 


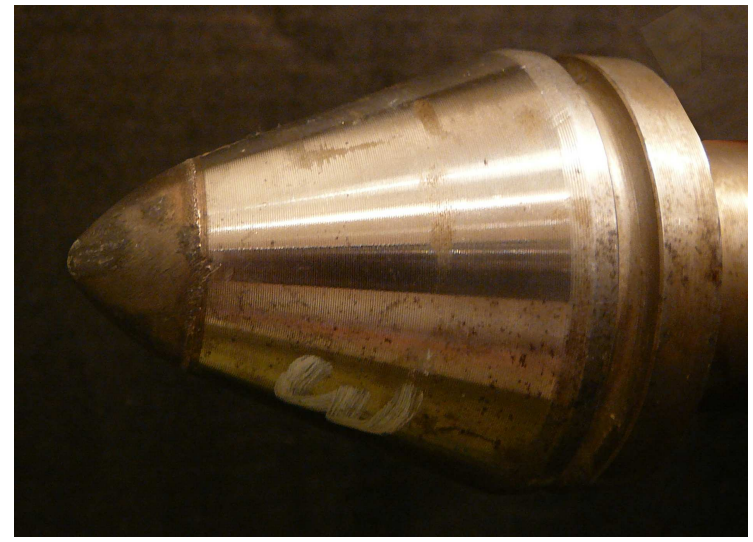

a)

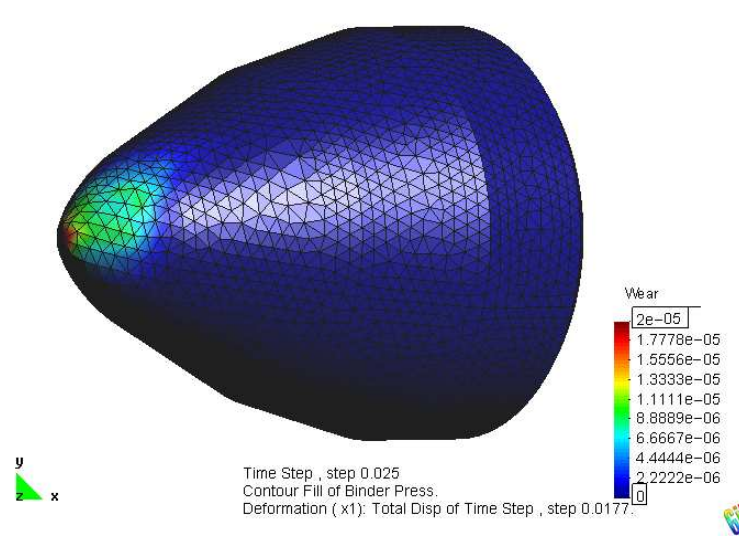

b)

Figure 16: Wear pattern on the tool surface: a) laboratory test, b) numerical simulation

\section{Simulation of the linear cutting test}

The linear cutting test has been simulated. Figure 17a shows the model geometry, consisting of the disc cutter and a rock sample. Only the area of the cutter ring interacting directly with the rock is considered. A rock sample with dimensions of $400 \times 150 \times 50 \mathrm{~mm}$ is represented by an assembly of randomly generated and densely compacted 40449 spherical elements of radii ranging from 0.8 to $6.0 \mathrm{~mm}$. The granite properties are assumed in the simulation, appropriate DEM parameters being evaluated. The disc cutter is treated as a rigid body and discretized with triangular facets. The parameters describing the disc interaction with the rock are as follows: contact stiffness modulus $k_{n}=10 \mathrm{GPa}$, Coulomb friction coefficient $\mu=0.8$. The velocity of the disc cutter is assumed to be $10 \mathrm{~m} / \mathrm{s}$.

Figure $17 \mathrm{~b}$ shows the cutter disc during cutting. Normal contact force history is shown in Fig. 18. Numerical results have been compared with experimental ones provided by Herrenknecht AG. A good agreement between the numerical and average experimental values is clearly seen.
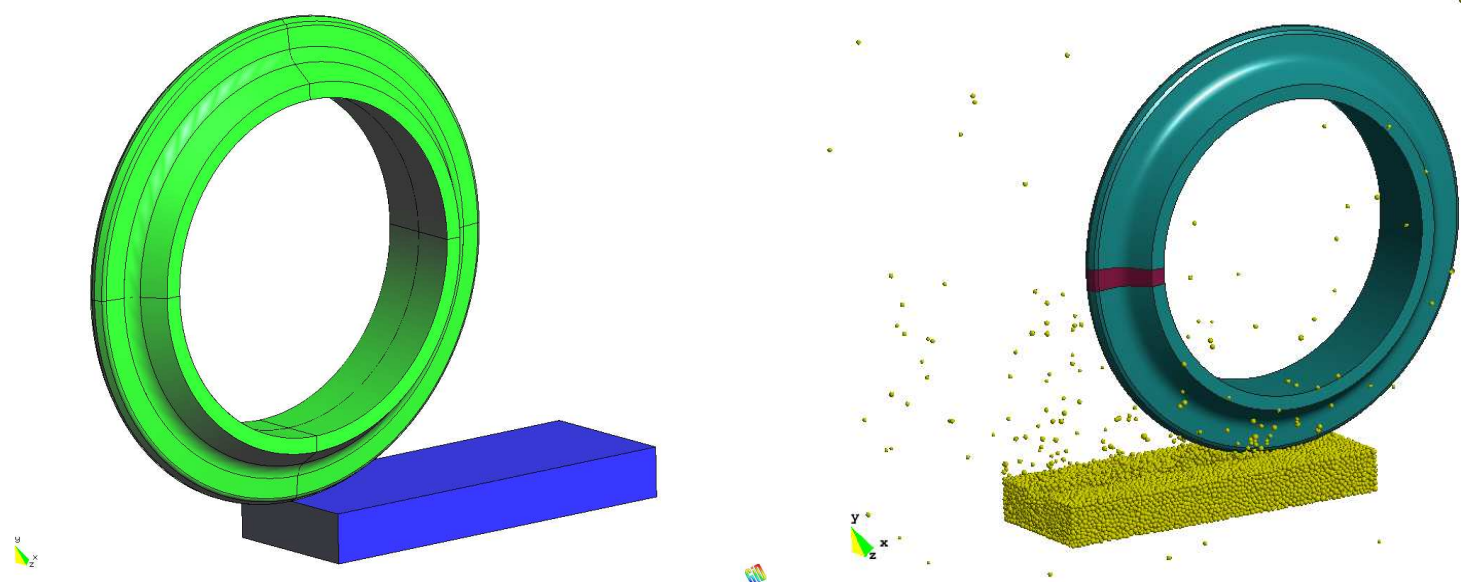

a)

Figure 17: Simulation of the linear cutting test: a) model geometry, b) simulation of cutting.

\section{Concluding remarks}

The numerical model of rock cutting developed within the framework of the discrete element model predicts correctly cutting action of the tools in underground excavations with roadheaders and TBMs. In particular, computer simulation allows us to estimate cutting forces, tool temperature and wear pattern under different process parameters. A supplementation of the cutting testrig investigations by numerical simulations would add significant advantages for further optimisation of the cutting tools and cutting process, since such simulations would allow more detailed principal parameter studies in much shorter time and at lower cost. 


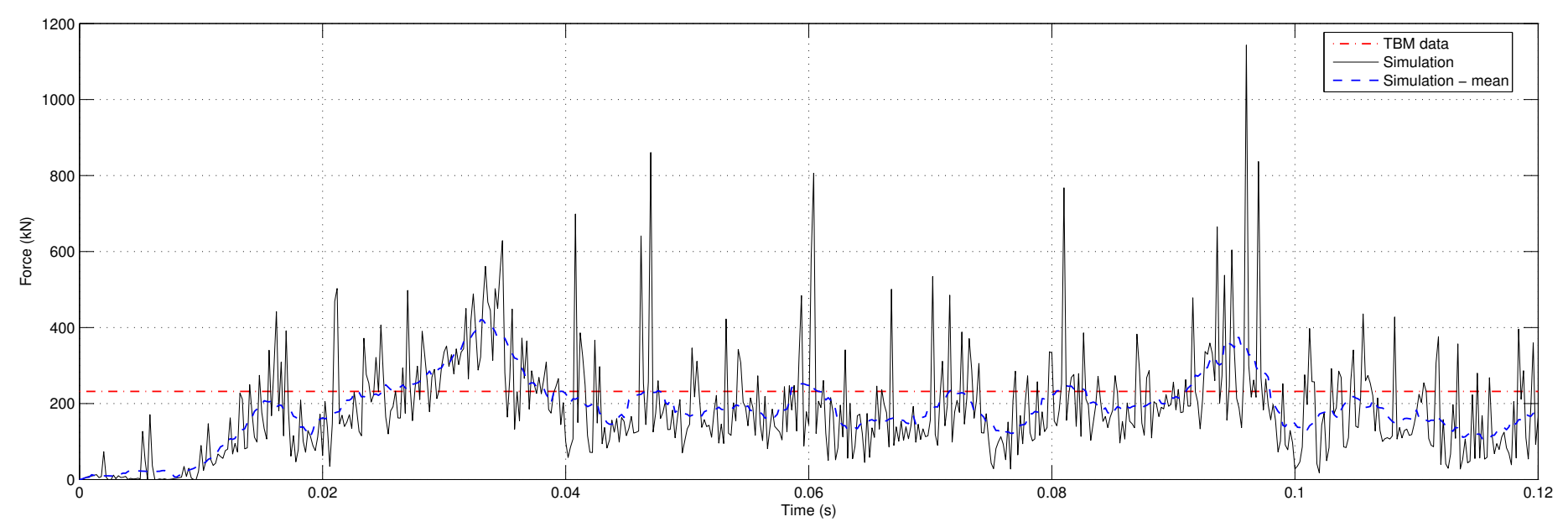

Figure 18: Normal force history

Acknowledgment

The work has been sponsored by the EU project TUNCONSTRUCT (contract no. IP 011817-2) coordinated by Prof. G. Beer (TU Graz, Austria). Authors thank Karin Bäppler and Florian Köppl from Herrenknecht AG for providing information on different aspects of rock cutting with TBMs.

\section{REFERENCES}

Akerman, J. (2006). Wear of rock cutting tools. VOEST-ALPINE Bergtechnik.

Archard, J. (1953). Contact and rubbing of flat surfaces. J. Appl. Phys. 24(8), 981-988.

Chang, S.-H., S.-W. Choi, G.-J. Bae, and S. Jeon (2006). Performance prediction of TBM disc cutting on granitic rock by the linear cutting test. Tunnelling and Underground Space Technology 21, 271.

Cundall, P. (1988). Formulation of a Three Dimensional Distinct Element Model — Part I. A Scheme to Detect and Represent Contacts in a System of Many Polyhedral Blocks. Int. J. Rock Mech., Min. Sci. \& Geomech. Abstr. 25(3), 107-116.

Cundall, P. and O. Strack (1979). A discrete numerical method for granular assemblies. Geotechnique 29, $47-65$.

Huang, H. (1999). Discrete Element Modeling of Tool-Rock Interaction. Ph. D. thesis, University of Minnesota.

Loui, J. and U. R. Karanam (2005). Heat transfer simulation in dragpick cutting of rocks. Tunnelling and Underground Space Technology 20, 263-270.

Oñate, E. and J. Rojek (2004). Combination of discrete element and finite element methods for dynamic analysis of geomechanics problems. Comput. Meth. Appl. Mech. Eng. 193, 3087-3128.

Rabinowicz, E. (1995). Friction and wear of materials. John Wiley \& Sons.

Rojek, J. (2007). Modelling and simulation of complex problems of nonlinear mechanics using the finite and discrete element methods (in Polish). Habilitiation Thesis, Institute of Fundamental Technological Research Polish Academy of Sciences, Warsaw.

Rojek, J., E. Oñate, F. Zarate, and J. Miquel (2001). Modelling of rock, soil and granular materials using spherical elements. In 2nd European Conference on Computational Mechanics ECCM-2001, Cracow, 26-29 June.

Verhoef, P. (1997). Wear of rock cutting tools. Balkema, Rotterdamd. 